\title{
CAMINHOS DA EDUCAÇÃO SOCIALISTA ${ }^{1}$
}

Maria Ciavatta ${ }^{2}$

\begin{abstract}
Resumo
O objetivo principal deste texto foi situar a pedagogia socialista no contexto histórico das sociedades onde se realizaram algumas experiências. Abordamos 0 tema em três momentos: questões conceituais e sua historicidade; o contexto dos processos revolucionários onde gerou-se a ideia também revolucionária da emancipação humana e da pedagogia socialista; por último, algumas experiências realizadas segundo esse ideário de homem e de sociedade, na Revolução Russa, na Revolução Cubana e no Movimento dos Trabalhadores Rurais sem Terra (MST).
\end{abstract}

Palavras-chave: pedagogia socialista; historicidade; revoluções

\begin{abstract}
The main objective of this text was to situate the socialist pedagogy in the historical context of the societies where some experiences were realized. We approach the theme in three moments: conceptual questions and their historicity; the context of the revolutionary processes where the revolutionary idea of human emancipation and socialist pedagogy was generated; and finally, some experiments carried out according to this ideology of man and society, in the Russian Revolution, in the Cuban Revolution and in the Landless Workers' Movement (MST).
\end{abstract}

Keywords: socialist pedagogy; historicity; revolutions

\section{Introdução}

A história da humanidade percorreu um longo caminho até chegar ao que hoje chamamos de educação socialista. Esta concepção da educação dos mais jovens pelas primeiras gerações não surgiu como uma abstração intelectual. Sua origem enraíza-se na história dos povos, nas formas de lavrar e plantar a terra, de

\footnotetext{
1 DOI: https://doi.org/10.22409/tn.16i29.p4553

2 Licenciada em Filosofia, Doutora em Ciências Humanas (Educação-PUC-RJ, 1990); Posdoutorado na Universitá di Bologna (1995-96) e na Università di Roma (2017); Professora Titular de Trabalho e Educação, Associada ao Programa de Pós-Graduação em Educação da Universidade Federal Fluminense (UFF), Niterói, RJ; Pesquisadora do CNPq. Coordenadora do Grupo THESE - Projetos Integrados de Pesquisa em Trabalho, História, Educação e Saúde (UFFUERJ-EPSJV-Fiocruz.
}

TrabalhoNecessário- www.uff.br/revistatrabalhonecessario: ano 16, №29/2018 
colher os frutos e produzir a sobrevivência humana. Em linhas gerais, podemos registrar o trabalho na terra, a produção agrícola e os instrumentos rudimentares, o artesanato e a arte, a manufatura e o nascimento das fábricas.

Em todos esses processos, o ser humano usou as mãos, o corpo, o cérebro, constituindo a unidade trabalho manual, trabalho intelectual. A predominância aparente de uma ou outra capacidade de pensamento e de ação foi introduzindo diferenciações entre os gêneros, homens e mulheres, e entre os do mesmo gênero, constituindo diferentes classes de indivíduos na sociedade e nas famílias. Estaria aí, em uma análise muito simplificada, sem considerar a posse da terra e outros meios de produção, o nascimento da divisão do trabalho, assegurando a uns ou a outros os trabalhos necessários à sobrevivência, e a educação para as funções transmitidas de geração em geração.

O fim do feudalismo e o nascimento das fábricas, a Revolução Industrial a partir do século XVIII e o desenvolvimento do modo de produção capitalista vão introduzir novos meios e critérios de relações produtivas. Não se trata apenas do poder da máquina de potencializar o trabalho humano. A própria palavra trabalho adquire novo significado, deixa de indicar uma atividade penosa, ligada à pobreza, para se tornar fonte de riqueza com acesso diferenciado pelos servos e senhores.

Foi um admirável processo de criar ciência, tecnologia, beleza e acenos de bem-estar pela redução dos trabalhos penosos, com o advento das máquinas, esperança que não se confirmou para todos. Foi, também, uma nova forma de "organizar e disciplinar o trabalho através de uma sujeição completa da figura do próprio trabalhador" (DEDDECA, 1985, p. 8-10).

A educação não esteve alheia a esses processos, que se desenvolveram pari passu com a organização das classes, frações de classes e grupos sociais na apropriação diferenciada e desigual dos produtos da riqueza social. Aos donos dos meios de produção ficou reservado o planejamento, o mando na organização do trabalho e a apropriação do tempo excedente do trabalho empregado nas atividades produtivas.

Aos trabalhadores que vendem sua força de trabalho, cabem os salários estimados, na melhor das hipóteses, para suprir as necessidades básicas da sobrevivência. Nestas primeiras décadas do século XXI, com o agravamento da submissão dos trabalhadores às exigências do capital (vínculos precários,

TrabalhoNecessário- www.uff.br/revistatrabalhonecessario: ano 16, №29/2018 
subemprego, desemprego, baixas condições de vida), nem mesmo as necessidades básicas (alimentação, saúde, educação, moradia, saneamento, segurança, previdência) estão sendo asseguradas.

Desde a socialização para o aprendizado das artes e dos ofícios na família e nas corporações, a educação foi se tornando mais complexa. Sob a produção capitalista, gerida com o apoio do Estado, os processos educacionais se institucionalizaram até a atual mercantilização da educação sob as empresas corporativas e a privatização que conduziu a educação ao mercado de ações. Sob a existência da desigualdade das classes sociais, prevalece a distinção básica entre os que, supostamente, pensam e aqueles que executam.

Marx (1980), na sua obra magistral, O Capital, responde aos pensadores do aperfeiçoamento das atividades laborais no sentido do disciplinamento dos trabalhadores, da formação estrita para atividades funcionais à produção e à acumulação do capital. Resume em poucas linhas o que deveria superar essa distinção de classe, o que seria um princípio básico da educação socialista:

Do sistema fabril, como expõe pormenorizadamente Robert Owen, brotou o germe da educação do futuro que combinará o trabalho produtivo de todos os meninos além de uma certa idade com o ensino e a ginástica, constituindo-se em método para elevar a produção social e de meio de produzir seres humanos plenamente desenvolvidos (MARX, 1980, p. 554, [grifo nosso]).

A ideia de "seres humanos plenamente desenvolvidos" no ideário socialista foi denominada educação politécnica ou tecnológica por Marx. Na mesma sintonia de princípios, Gramsci (1981, entre outros), fala no trabalho como princípio educativo, em educação omnilateral, em uma escola unitária, para todos. Em termos aproximados a essas concepções, no Brasil, traduziu-se no ideário socialista na busca de uma educação democrática, de qualidade, com base no conhecimento dos fundamentos histórico-sociais e científico-tecnológicos do trabalho, na defesa da formação integral do ser humano, pela educação politécnica ou tecnológica, pelo ensino integrado entre a formação geral e a educação profissional. ${ }^{2}$

Em qualquer uma dessas denominações, prevalece a ideia da superação das desigualdades e das classes sociais geradas pela divisão social do trabalho e

2 Para a gênese histórica dessa concepção, ver Frigotto, Ciavatta e Ramos, 2005.

TrabalhoNecessário- www.uff.br/revistatrabalhonecessario: ano 16, №29/2018 
pela reprodução e acumulação capitalista da riqueza social pelas classes abastadas. Mas a ideia da educação socialista será uma abstração, se não a concebermos na sua historicidade, no tempo e no espaço da vida de cada povo e de cada situação em que foi tentada sua implementação, com vistas a uma educação emancipadora. Por isso, o delineamento dos caminhos da educação socialista, nesta apresentação, se fará em três momentos: no primeiro, questões conceituais e sua historicidade; segundo, o contexto dos grandes processos revolucionários onde gerou-se a ideia, também revolucionária, da emancipação humana e da pedagogia socialista; por último, algumas experiências realizadas segundo esse ideário de homem e de sociedade na Revolução Russa, na Revolução Cubana e na perspectiva da pedagogia socialista do Movimento dos Trabalhadores Rurais sem Terra (MST).

\section{Questões conceituais e sua historicidade}

Mesmo no Brasil, onde as traduções em língua portuguesa costumam sofrer alguma defasagem de publicação em relação aos originais e traduções em línguas de maior difusão (inglês, francês, espanhol), o tema pedagogia socialista não é novo na literatura. Ainda mais porque sua fundamentação teórica está em alguns escritos de Marx, de Gramsci e de Lukács, publicados nas últimas décadas no Brasil. Sobre a educação socialista, as primeiras publicações tornaram-se livremente acessíveis nos últimos anos da Ditadura e após seu final (1964-1985). ${ }^{3}$

A concepção de trabalho ${ }^{4}$ constitui um princípio básico da educação socialista. Trata-se de entender a importância fundamental do trabalho como princípio ontológico, fundante da constituição do gênero humano que, como ser da natureza e distinto dela, não prescinde, pela atividade física e mental, de retirar da natureza os meios de vida. É o que o torna um ser social que produz e compartilha com os demais o conhecimento, a cultura, os bens e a sociabilidade

\footnotetext{
${ }^{3}$ Em português, a exemplo de: Rossi (1981 e 1982); Pistrak (1981); Makarenko (1985); Capriles (1989); Nogueira (1990); Manacorda (1990); Nosella (1992). São mais recentes: Pistrak (2009); os verbetes sobre pedagogia socialista, educação politécnica, escola única do trabalho, escola unitária em Caldart et al. (2012); Shulgin (2013); Krupskaia (2017); Abreu (2017). Em espanhol, alguns exemplos: Gramsci (1981); Castles e Wüstenberg (1982); Botello (1987).
}

${ }^{4}$ Algumas destas reflexões constam de Frigotto e Ciavatta, 2012. 
gerados pelo trabalho na produção e na reprodução da existência (LUKÁcS, 1978). "O momento essencialmente separatório é constituído não pela fabricação de produtos, mas pelo papel da consciência" que produz a ideação de cada gesto, de cada produto, o que Marx considera um resultado que já existia de modo ideal na "representação do trabalhador" (idem, p. 4).

Nesse ato fundamental, em tempo- espaços determinados, Marx baseia sua concepção de história dos indivíduos, dos grupos e classes sociais (MARX; ENGELS, 1979). Na relação entre o trabalho e a educação em todas as suas formas, afirma-se o caráter formativo do trabalho e da educação como ação humanizadora através do desenvolvimento de todas as potencialidades do ser humano (CIAVATTA, 2009).

Em uma concepção dialética, o trabalho humano é a forma mediante a qual, em qualquer tempo histórico, define-se o modo humano de existir. Dado seu potencial de formação humana, mesmo nas formas mais brutais da escravidão, o trabalho não é pura negatividade. De modo que o escravo, ainda que não reconhecido como tal, tratado como simples meio de produção, é um ser humano e não se reduz a um objeto, resiste, inventa e cria espaços de vida espiritual, de cultura, de liberdade e de humanização (entre outros, MATTOS, 2009). Não fosse assim, teria sido impossível superar as relações de servidão, as escravocratas e as novas formas de opressão e mercantilização do modo capitalista de produção.

Neste nível de realização estariam todos os valores de uso. $\mathrm{Na}$ análise da gênese do capital, Marx (1980) vai opô-los aos valores de troca, os bens que também servem à reprodução da vida humana, mas estão sujeitos a apropriação por outros, à situação de compra e venda como mercadorias. Inclui-se aí o trabalho como força de trabalho, sujeita à divisão técnica e social do trabalho, vendida como tempo de trabalho aos donos dos meios de produção. O salário ou remuneração recebida pelo trabalhador exclui o tempo de trabalho excedente ao valor contratado para a produção, que é apropriado pelo dono do capital. ${ }^{5}$

Em ambas as situações, como valor de uso ou como valor de troca, o trabalho é educativo no sentido que gera disposições físicas e mentais, relações sociais que operam na sua positividade ou na sua negatividade, na dependência

\footnotetext{
${ }^{5}$ Marx (1980) aprofunda a compreensão desse fenômeno na análise do fetiche da mercadoria em que o trabalhador é alienado do produto do trabalho, do conhecimento e da sociabilidade gerados pelo trabalho coletivo.
}

TrabalhoNecessário- www.uff.br/revistatrabalhonecessario: ano 16, №29/2018 
do contexto do trabalho executado e de sua apropriação pelo próprio trabalhador ou por outrem. Quando falamos em educação ou pedagogia socialista remetemos o termo à sua historicidade, aos processos de resistência à dominação e, principalmente, aos processos revolucionários que buscam a transformação das estruturas sociais de dominação nas suas formas servis, escravocratas, assalariadas, desregulamentadas e precarizadas progressivamente, nas últimas décadas.

Karl Marx, como analista agudo de seu tempo, no coração do nascente capitalismo industrial, na Inglaterra, sensibiliza-se com as condições penosas, insalubres dos trabalhadores, onde se incluíam também as crianças em trabalhos exaustivos. Nos esparsos textos em que o autor escreve sobre a educação, juntamente com Engels, volta-se para as experiências dos socialistas utópicos, particularmente Robert Owen. Como industrial, Owen desenvolveu ações públicas junto ao governo e no interior de suas indústrias, de proteção e regulamentação do trabalho das crianças, a criação de creches para crianças a partir de dois anos (ABREU, 2017).

O socialismo de Marx e Engels, que Engels chamou de socialismo científico, contrastava com os ideais dos socialistas utópicos que propunham modelos de ordem social transcendentes à sociedade de seu tempo e que haveriam de realizar-se um dia. Marx (1980) reconhece o caráter inovador, revolucionário da indústria moderna "que nunca considera, nem trata como definitiva a forma existente de um processo de produção. Sua base técnica é revolucionária, enquanto todos os modos anteriores de produção eram essencialmente conservadores" (MARX, 1980, p. 557).

Não é de se estranhar que ele considere as escolas politécnicas e agronômicas como "fatores desse processo de transformação", assim como "as escolas de ensino profissional onde os filhos dos operários recebem algum ensino tecnológico" e a iniciação nos instrumentos produtivos. Mas, talvez, o argumento principal de sua defesa da educação politécnica seja entender que "A legislação fabril arrancou ao capital a primeira e insuficiente concessão de conjugar a instrução primária com o trabalho na fábrica" (op. cit., p. 559).

O trabalho como princípio educativo em termos gramscianos (GRAMSCI, 1981) constitui-se em uma alternativa pedagógica em favor da educação omnilateral, completa no sentido de desenvolver toda a potencialidade dos

TrabalhoNecessário- www.uff.br/revistatrabalhonecessario: ano 16, №29/2018 
alunos. No mundo moderno e contemporâneo, as escolas assumem o trabalho como princípio pedagógico que se realiza em uma dupla direção. Sob as necessidades do capital, da formação de mão de obra para as empresas, o trabalho educa para a disciplina, para a adaptação às suas formas de exploração ou, simplesmente, para o adestramento nas funções úteis à produção.

Mas sob a contingência das necessidades dos trabalhadores, o trabalho não deve somente preparar para o exercício das atividades fabris, técnicas ou tecnológicas, no campo e na cidade. Deve propiciar o acesso à compreensão e ao uso qualificado dos processos técnicos, científicos e histórico-sociais que the são subjacentes, que sustentam as artes, a comunicação, a introdução das tecnologias e da organização do trabalho (FRIGOTTO; CIAVATTA, 2012).

É importante acrescentar nestas últimas notas sobre questões da educação socialista, o conceito de totalidade social que organiza internamente toda obra de Marx, e tem sua argumentação clássica no Método da Economia Política (1977). " A população é uma abstração se desprezarmos, por exemplo, as classes de que se compõe. Por seu lado, "as classes são uma palavra oca se ignorarmos os elementos em que repousam, por exemplo, o trabalho assalariado, o capital etc." (MARX, 1977, p. 229). Poderemos alcançar o conhecimento de uma determinada população, não na abstração da semântica do termo, mas como "totalidade viva", como "síntese de múltiplas determinações" (idem, p. 228-29).

Assim, também, a historicidade da educação e da pedagogia socialista somente pode ser compreendida no conjunto das relações que a determinam no tempo e no espaço dos processos revolucionários. Estes abalaram o mundo em diferentes lugares e temporalidades, nas lutas pela transformação de todas as estruturas de opressão econômica, política, social, educacional.

\section{"O mundo de ponta-cabeça" nos processos revolucionários"}

Não se pode compreender, em profundidade, as partes, independente do todo que the dá sentido e significado. Assim, também, não se pode entender o movimento dos povos e grupos sociais em direção a um mundo emancipado dos grilhões que prendem a vida humana, fora do contexto das grandes mobilizações, das revoltas populares e das revoluções que tiveram curso no mundo ocidental onde vivemos.

TrabalhoNecessário- www.uff.br/revistatrabalhonecessario: ano 16, №29/2018 
A história registra processos lentos como a longa duração das estruturas de Braudel (1982) e processos de tempos médios e breves. Não cabe, nas dimensões e nos objetivos deste texto, uma digressão sobre a história das revoltas no mundo. Mas é ilustrativa a menção às grandes revoluções, sejam as de pensamento, sejam as de luta armada. Todas se realizam mediante grandes inversões dos poderes políticos, instituídos sob diversas formas de dominação, de modo predominante, escravidão e servidão, pobreza, mas também de inconformidade, de ideias mobilizadoras para a transformação.

Nesta seção, trataremos, brevemente, de alguns desses grandes movimentos de transformação: o Renascimento, a Revolução de Copérnico, a Reforma Protestante, a Revolução Científica de Darwin, a Revolução Inglesa, a Revolução Francesa e a Revolução Russa. ${ }^{6}$

Começamos por um dos fenômenos mais polêmicos entre os historiadores, o sentido do momento histórico do Renascimento, cujo contexto está associado à crise do feudalismo e ao surgimento do capitalismo na Europa Ocidental, a partir do século XIV. O Renascimento, o Humanismo, a Reforma Protestante teriam sido expressões dessa crise que assinala a ascensão de grupos sociais que buscavam contestar as explicações católicas e feudais e explicar seu papel no universo. O ápice do movimento de Renascimento nas letras e nas artes "foi na Itália rica, comercial e urbanizada", com os grandes artistas do período, Michelangelo e Rafael, entre outros (SILVA, 2005, p. 359-62).

Nos movimentos econômicos e culturais que se sucedem e se completam ao longo dos séculos, outras grandes inversões de pensamento e de poder político podem ser ilustrativas dos avanços e percalços da humanidade na sua dialética da transformação. A Revolução de Copérnico (1473-1543), segundo a qual a Terra gira em torno do Sol, e não o contrário, desafiou a verdade da Igreja Católica, detentora do saber último e da explicação divina sobre as origens dos processos que regem a vida humana. Pelos seus estudos de astronomia, sustentados arduamente por Kepler, Copérnico desafiou e inverteu os poderes constituídos, abrindo espaço para a ciência moderna (JAPIASSÚ, 1985).

\footnotetext{
${ }^{6}$ Pelas dimensões deste texto, não trataremos das guerras de libertação dos países da América Latina no século XIX, de outro importante processo revolucionário, a Revolução Mexicana, que tomou o ideário da educação socialista como base para a organização do sistema educacional do México na primeira metade do século XX.
}

TrabalhoNecessário- www.uff.br/revistatrabalhonecessario: ano 16, №29/2018 
Também pela Reforma Protestante (1517), Martinho Lutero (1483-1546) afrontou as autoridades eclesiásticas em defesa do direito do livre exame da palavra dos livros sagrados, subtraindo sua interpretação à autoridade máxima católica, o papa.

Não menos importante foi o fenômeno do lluminismo (século XVII - XVIII). Surgiu na França e defendia o domínio da razão sobre a visão teocêntrica. Tratava-se de eliminar as "trevas" que obscureciam o pensamento e a sociedade desde a Idade Média. Também chamado "Século das Luzes", os filósofos iluministas (citem-se John Locke, Voltaire, Rousseau entre outros), reafirmavam que, pela razão e pelo conhecimento, o homem, centro do mundo, seria capaz de buscar respostas para seus problemas.

Na mesma linha de confronto, mas sem apelo popular na época, salvo a polêmica nos meios eclesiais e científicos, a Revolução Científica de Charles Darwin (1809-1882), em meio a uma vida de viagens, de estudo e de temores pela repercussão das próprias ideias, afirmou a evolução das espécies, negando, ipso facto, o mito bíblico da criação do ser humano. Com seu rigor na descrição das espécies nos lugares mais primitivos da terra, como as Ilhas Galápagos, gerou a oposição que perdura até hoje em diversas denominações religiosas.

Citando as revoluções armadas no mundo ocidental europeu, o fenômeno mais geral das "revoluções burguesas", estaria datado nos séculos XVII e XVIII, entre 1640, marco inicial da Revolução Inglesa, e 1789, marco da Revolução Francesa. ${ }^{7}$ São revoluções que tinham por inspiração as ideias iluministas de liberdade, dos direitos do homem em oposição ao absolutismo, à monarquia, à aristocracia, aos títulos de nobreza.

Christopher Hill (1987), em seu livro clássico sobre a Revolução Inglesa de 1640, fala em The world upside down ${ }^{8}$ e dá os elementos mais gerais de uma revolução: "Durante muitos séculos as revoltas populares constituíram uma característica essencial da tradição inglesa, e as décadas centrais do século XVII presenciaram a maior revolução que já ocorreu na Grã-Bretanha" (HILL, 1987, p.

\footnotetext{
${ }^{7}$ https://pt.wikipedia.org/wiki/Revolu\%C3\%A7\%C3\%A3o Industrial; Acesso em 010-10-2017

${ }^{8}$ Falando sobre a tradução, Renato Janine Ribeiro, o tradutor, explica: "O termo poderia ser traduzido de diversas formas: o mundo de ponta-cabeça, mas também o mundo de cabeça para baixo, o mundo girado de cabeça abaixo, o mundo de pernas para o ar. Todas aparecem no texto. Todas são uma só" (p. 21). Como paulista que é, o tradutor escolheu o termo comum no estado e o mais expressivo do sentido amplo dessa Revolução, o mundo de ponta-cabeça.
}

TrabalhoNecessário- www.uff.br/revistatrabalhonecessario: ano 16, №29/2018 
29). E explicita a gênese da Revolução Inglesa: "as tentativas de vários grupos, formados em meio à gente simples do povo, para imporem as suas próprias soluções aos problemas de seu tempo" (idem, p. 30-31). Identifica, mais adiante, os interesses e os sujeitos sociais daquela época, propondo soluções políticas, econômicas, religiosas, sociais, educacionais. Sua história é escrita sobre as ideias e ações dos setores populares.

Outra grande transformação foi a passagem do sistema doméstico para o de fábrica, sobre a qual convencionou-se o nome de Revolução Industrial, na segunda metade do século XVIII. Foi a transição do artesanato e dos ofícios para os processos de manufatura, por máquinas, processos químicos, produção de ferro, uso de novas fontes de energia (água, vapor), máquinas-ferramenta (IGLÉSIAS, 1982). Registra-se seu início na Inglaterra e nos Estados Unidos, alimentada também pelo jugo e colonização de outros povos, expandindo o livre mercado para outros continentes e seus países, em busca de matérias primas.

A Revolução Francesa, em 1789, eclodiu em um período de extrema agitação política e social na França, sob a influência das grandes transformações de vida do povo com o fim do feudalismo, as novas relações de produção que expandiam a urbanização e a organização do trabalho sob o poder político e econômico da burguesia ascendente (DEDDECA, 1985).

Hobsbawn (1982) situa a Revolução Francesa como a grande revolução (1789-1848), como "um levante gêmeo" da Revolução Industrial nos dois Estados rivais, França e Grã-Bretanha. Para o autor, não teria sido:

"o triunfo da 'indústria', mas da indústria capitalista; não da liberdade e da igualdade em geral, mas da classe média ou da sociedade 'burguesa' liberal; não da economia moderna ou do Estado moderno, mas da economia e Estados em uma determinada região geográfica" (HOBSBAWN, 1982, p. 17, grifos do autor).

Não nos deteremos nas Guerras de Libertação que, bem ou malsucedidas, atravessaram todos os continentes nos países colonizados pelos europeus. Citem-se a independência das colônias latino-americanas, do México à Argentina; as africanas, a exemplo de Angola e Moçambique, as lutas antirracistas na África do Sul. 
O outro abalo político e social de grande repercussão foi a Revolução Socialista, a Revolução Russa que tem seu marco simbólico em 1917 e, no ano de 2017, completou 100 anos. Deve ser vista no contexto do mundo em transformação pelo capitalismo. Hobsbawn (1988), em A era dos impérios, detalha vários acontecimentos que sinalizam os movimentos em marcha que são parte do contexto de onde emerge a grande Revolução Socialista. Mencionaremos apenas alguns deles.

"O fato maior do século XIX é a criação de uma economia global única que atinge progressivamente as mais remotas paragens do mundo". São transações econômicas, comunicações e intercâmbios de bens, dinheiro e pessoas que dos países "ligando os países desenvolvidos entre si e ao mundo não desenvolvido" (op. cit., p. 95). ${ }^{9}$ Com o novo imperialismo do capital - não apenas dos títulos de nobreza da autocracia - surgem também os movimentos operários, as políticas democráticas e "a tentativa de utilizar a expansão imperial para diminuir o descontentamento interno por meio do avanço econômico ou reforma social, ou de outras maneiras" (idem, p. 105).

Na Rússia czarista, quem se mobilizava para a ação política, "em partidos e movimentos de explícita base de classe", eram as massas operárias, mediante alianças, coalizões e "frentes populares". (id., p. 131). Mobilizavam-se, também, "grupos de cidadãos unidos por lealdades setoriais, como as de religião e as de nacionalidade" (id., p. 133). A classe operária crescia e, com ela, a ameaça "sobre a ordem estabelecida na sociedade e na política. Que aconteceria se os operários se organizassem politicamente como classe?" (id. p. 169).

Foi precisamente o que aconteceu, em escala europeia e com extraordinária velocidade. Onde quer que a política democrática e eleitoral o permitisse, apareciam em cena, crescendo com rapidez assustadora, os partidos de massas baseados na classe operária, em sua maior parte inspirados na ideologia do socialismo revolucionário (pois todo socialismo era, por definição considerado revolucionário) e liderado por homens - e às vezes por mulheres que acreditavam nessa ideologia (HOBSBAWN,1988).

${ }_{9}^{9}$ Sobre mundo não desenvolvido, v. Hobsbawn (1982), cap. 3 (indicação do autor).

TrabalhoNecessário- www.uff.br/revistatrabalhonecessario: ano 16, №29/2018 


\section{A historicidade da pedagogia socialista}

A pedagogia socialista, além de ser um ideário nascido das ideias de emancipação, das revoltas e de grandes revoluções, é uma concepção de ser humano e de educação. Por princípio, contesta as formas de dominação, exploração e degradação a que povos, classes e grupos sociais podem ser submetidos. Mas a concepção de educação do homem, como ser plenamente desenvolvido em todo seu potencial, realiza-se na dependência da história das diferentes sociedades. Sua elaboração teórica e prática sempre teve vínculos orgânicos, com experiências de luta social e política, concepções particulares de formação humana, tendo à frente a concepção hegemônica do capital que impõe a forma mercadoria "como marco de construção de sua subjetividade e materialidade histórica" (CIAVATTA; LOBO, 2012, p. 561). ${ }^{10}$

Este pressuposto é vital para entendermos os caminhos da construção da pedagogia socialista na Rússia após a Revolução de 1917 e em Cuba após a Revolução Cubana, vitoriosa em 1959. Sua historicidade permite compreender a gênese do ideário da educação socialista no Brasil, ${ }^{11}$ país que não passou por processos semelhantes, apenas teve muitas revoltas populares obscurecidas pela história. Recuperamos também alguns aspectos de uma análise crítica sobre a educação socialista e a perspectiva da pedagogia socialista do Movimento dos Trabalhadores Rurais Sem Terra.

\section{A experiência da educação socialista russa}

A relação dialética entre a consciência e o modo de produzir a vida está no cerne dos processos revolucionários. A Revolução Russa vitoriosa em 1917 teve grandes embates na dinâmica das estratégias de organização da sociedade e da educação. Neste trabalho, será considerado apenas o período que vai até 1929, sob a ação do Comissariado do Povo para a Educação, sob o comando dos

\footnotetext{
${ }^{10}$ Esta seção tem por base Ciavatta e Lobo (2012).

${ }^{11}$ Referimo-nos à proposta de educação politécnica da Projeto de Lei de Diretrizes e Bases da Educação na segunda metade dos anos 1980 (entre outros, SAVIANI, 1997) e à proposta de formação integrada pelo Decreto n. 5.154/2004, incorporada à LDB n. 9.394/96 pela Lei $n$. 11.741/2008, subsumida na contra-reforma do Ensino Médio pela Lei n.13.415/2017 e, praticamente, inviabilizada pelo contexto dos conteúdos da Lei e pela situação de corte de recursos com a aprovação do "Teto do Corte de Gastos", EC n. 95/2016.
} 
primeiros educadores revolucionários: Krupskaia, Lunacharsky, Schulguin; as experiências de Pistrak e a Escola Comuna; Makarenko e as instituições educacionais correcionais. ${ }^{12}$ Tratava-se de para implantar a "nova sociedade" pelos ideais da "educação do futuro", a educação do "homem novo" que deveria crescer com a sociedade comunista.

Não foi a aplicação de um modelo, mas o trabalho de busca das melhores respostas aos problemas da Revolução, em um projeto que se iniciou com a "a contradição histórica da primeira revolução socialista [que] teve lugar, não no mais avançado país capitalista, mas em um país atrasado onde as forças produtivas e a estrutura da sociedade eram ainda semifeudais". Não havia ensino formal para a maioria dos operários e dos camponeses; ao menos três quartos da população eram analfabetos; os professores não estavam capacitados, tinham baixos salários e baixa posição social. A Igreja Ortodoxa dirigia a maioria das escolas (CASTLES e WUNSTEEMBERG, 1982, p. 66-69).

A população foi informada sobre as mudanças pretendidas: "educação geral, livre e obrigatória para todas as crianças e cursos especiais para os adultos"; "escola secular, unitária com diferentes níveis, para todos os cidadãos"; apoio para "o movimento educativo e cultural das massas trabalhadoras", assim como para "organizações de soldados e operários"; "os professores deveriam cooperar com outros grupos sociais" e se tomariam medidas imediatas para a "miserável situação material" dos mais pobres, os mais importantes trabalhadores culturais e os professores das escolas elementares. Cabia a Krupskaia a tarefa de projetar um novo sistema educativo e a Lunacharsky, a administração de todos os tipos de educação.

Ao Estado cabia assumir as escolas privadas e confessionais; entre outras medidas, fez-se a "separação entre Estado e Igreja e entre Igreja e escola"; buscando-se a "transformação de todas as escolas em escolas unitárias de trabalho", cuja estrutura fixava duas etapas: dos oito aos 13 anos (cinco anos de

\footnotetext{
${ }^{12}$ Sua metodologia de trabalho sofreu oposição do grupo Petrogrado de Educadores, liderado por Blonsky, "que aceitava a escola unitária de trabalho, mas pedia que se mantivessem a divisão entre as matérias, a forma de ensino sistematizada, um programa de estudos definido, e a diferenciação em diversos ramos do conhecimento no oitavo e no nono ano" (CASTLES e WUNSTEEMBERG, 1982, p. 75). A partir de 1931, com a ascensão de Joseph Stalin ao posto maior de comando do governo da URSS, adota-se uma política de desenvolvimento econômico que passa a exigir uma política educacional com base na formação técnica. A primeira equipe do Comissariado é desfeita ou se afasta de suas funções.
} 
estudo); e dos 13 aos 17 anos (mais quatro anos); e jardim de infância articulado às escolas para crianças de cinco a sete anos (id.p. 72-73).

$\mathrm{O}$ trabalho produtivo combinado à aprendizagem escolar era um elemento essencial da educação. Para Krupskaia, o princípio do trabalho deve ser "educativo e gratificante, e deve ser levado a cabo sem efeitos coercitivos sobre a personalidade da criança e organizado de forma social e planejada", para que desenvolva "uma disciplina interna, sem a qual o trabalho coletivo planejado racionalmente seria impensável". Ela e Lunacharsky enfatizavam que "a educação socialista não era somente uma questão de conteúdos, mas também de métodos. Rejeitavam a escola livresca e exigiam que as crianças aprendessem tomando parte no trabalho e na vida social” (id., p. 74-75, grifo nosso).

Com Schulguin (2013), defendiam o método complexo: "os professores não deviam ensinar seguindo um programa rígido, por matérias acadêmicas. Em vez disso, os aconselhava a tomar como ponto de partida os problemas das crianças, da produção local e da vida cotidiana e examiná-los, simultaneamente, à luz das várias disciplinas" (CASTLES e WUNSTEEMBERG, 1982, p. 74-75, grifo nosso). "O conceito de trabalho socialmente necessário" de Schulguin, "abre outras dimensões para o entendimento ampliado do trabalho como princípio educativo." Sua concepção articula ensino com trabalho produtivo desde a educação infantil (FREITAS, 2013, p. 9).

O livro de Schulguin (op. cit.) mostra as controvérsias com pedagogos dos países capitalistas (a exemplo de Kerchensteiner, Dewey) ${ }^{13}$, especialmente na relação da escola com o trabalho nas sociedades burguesas. Schulguin fala em "trabalho social", "aquele que produz algum resultado", que é "concreto", "tem valor pedagógico", "orientado para a melhoria da economia e da vida, para elevar o nível cultural do meio", que "está em conformidade com as forças dos adolescentes e com as particularidades de sua idade" (id., p. 89-91).

Outro nome memorável entre os grandes educadores do ideário pedagógico socialista é Pistrak. Ele tinha uma visão educacional concomitante à ascensão das massas na Revolução, "a qual exigia a formação de homens

\footnotetext{
${ }^{13}$ Georg Kerchensteiner (1854-1932), pedagogo alemão contemporâneo dos autores socialistas, defendia a escola do trabalho para desenvolvimento da inteligência prática e superação do intelectualismo livresco; John Dewey (1859-19524), filósofo e pedagogo norte-americano, era defensor da escola pública, do pragmatismo, da Escola Ativa, uma das bases da Escola Nova no Brasil.
}

TrabalhoNecessário- www.uff.br/revistatrabalhonecessario: ano 16, №29/2018 
vinculados ao presente, desalienados, mais preocupados em criar o futuro do que em cultuar o passado, e cuja busca do bem comum superasse o individualismo e o egoísmo" (TRAGTENBERG, 1981, p. 8-9).

O documento mais importante legado por Pistrak (1981) é o livro Fundamentos da Escola do Trabalho, prefaciado pelo autor em 1924. Pistrak fala das "dificuldades práticas" e da descoberta de uma "pedagogia social" pelo seu coletivo. As ideias "foram se tornando cada vez mais sólidas no processo de luta e nos encontros com professores primários em diversos momentos e em diferentes lugares, permitindo-nos que tomássemos consciência de experiência de outras escolas e demais instituições infantis" (PISTRAK, 1981, p. 26).

Os trabalhos de tradução do russo para o português de Luiz Carlos de Freitas com Alexey Lazarev e Natalya Pavlova têm permitido a ampliação da compreensão dos processos escolares em que se gerava a pedagogia socialista. Trazem também a discussão de questões específicas, como o caso da educação pelo trabalho, o politecnicismo, segundo Schulguin (op. cit.). Também a tradução do livro de Krupskaia (2017) traz novos elementos sobre os estudos e a prática da coordenadora do grande projeto coletivo que foi $A$ construção da Pedagogia Socialista ao longo de mais de dez anos de atividade.

Um trabalho, até recentemente, desconhecido entre nós, é uma obra coletiva de Pistrak (2009) e dos professores que trabalhavam com ele na EscolaComuna, uma escola experimental de demonstração, do Ministério da Educação. A Escola do Trabalho é detalhada nas questões relativas a uma pedagogia do trabalho educativo, tais como questões de direção, de política da juventude comunista e das diversas disciplinas escolares (Matemática, Física, Ciências Naturais etc.).

Makarenko tem uma trajetória particular. Era ucraniano e iniciou suas atividades ainda no período czarista. Mas seu legado para a pedagogia socialista vem de 1920, quando passou a dirigir instituições educacionais "correcionais" para crianças e adolescentes abandonados: a Colônia Maxím Gorki (1920 a 1928) e a Comuna Dzerzinski (1927 a 1935). Sua inserção no projeto educacional da Revolução ocorreu no momento em que o Estado soviético proporcionou todas as condições para a educação, inclusive com a redução do horário de trabalho em duas horas para todos os que estudavam. E "era permitido aproveitar as Casas 
do Povo, igrejas, clubes, casas particulares e locais adequados nas fábricas, empresas e repartições públicas para dar aulas" (CAPRILES, 1989, p. 30-31).

Desses autores, Makarenko parece ter sido o único a permanecer à frente de instituições educativas depois de 1930, mantendo os princípios pedagógicos que sustentaram o êxito de suas atividades: o trabalho coletivo de educação e de gestão da instituição e o reconhecimento da "criança real, concreta, as diferentes personalidades e o modo pelo qual se desenvolve cada uma delas de forma diferenciada no processo de autogestão" (LUEDMANN, 2002, p. 19). Sua obra principal é o Poema Pedagógico (MAKARENKO, 1985) onde, de forma literária, ele expõe os princípios educacionais e suas experiências práticas nos coletivos das duas instituições que dirigiu.

\section{A educação socialista da Revolução Cubana ${ }^{14}$}

Como outras revoluções, a Revolução Cubana, quando foi vitoriosa no final do ano de 1959, iniciou o seu processo revolucionário das instituições, dos poderes, dos sujeitos sociais revolucionários de primeira hora, daqueles que os apoiaram e dos que contestavam o novo poder que se instalava no país. $\mathrm{O}$ governo revolucionário coerente com o ideário do socialismo do legado marxista e conhecedor de sua realização na URSS, levou adiante as medidas de desapropriação urbana e rural, coletivização inicial da agricultura, alimentação básica, alfabetização universalizada para toda a população, serviços de saúde públicos, nova Constituição, organização dos poderes executivos, legislativos e judiciários.

A história da Revolução Cubana faz parte do contexto dos países da América Latina, primeiro submetidos à colonização predatória da Espanha e de Portugal e, depois, submetidos ao capitalismo europeu e norte-americano. Cuba era um país secularmente dominado por ditaduras, gangsters, policiais, militares neocoloniais, conservadores escravistas, reformistas falsos. Houve momentos cruciais de disputa com o mundo capitalista, particularmente, os Estados Unidos que se opuseram desde sempre, a perder seu espaço de dominação, exploração e de lazer na ilha de Cuba.

${ }^{14}$ Esta seção tem por base Ciavatta (1992) e Ciavatta e Lobo (2012).

TrabalhoNecessário- www.uff.br/revistatrabalhonecessario: ano 16, №29/2018 
Mas os povos da América Latina tiveram no movimento cubano um exemplo de lutas de libertação, vitoriosas no empenho de implantar o ideário socialista. Foram lutas que alimentaram os sonhos e os movimentos políticos pelo fim das ditaduras no Brasil, no Chile, na Argentina, no Peru. Mas, talvez, nas condições de ausência de organização política, sob a tutela do autoritarismo e as condições de pobreza, a população brasileira se manteve embalada pelas promessas políticas e pelo medo à repressão.

Não obstante os avanços conseguidos após a redemocratização representativa do Brasil, nos anos 1980, prevalece a acomodação aos projetos desenvolvimentistas. Estes têm como referência as exigências do mercado produtivo e financeiro, e não o atendimento às necessidades básicas de subsistência da população (saúde, educação, moradia, trabalho, alimentação etc), fundamentais na construção de um regime socialista.

O historiador Pablo González Casanova (1987) relata que a Revolução Cubana "ocorreu em um país onde todos os projetos reformistas e nacionalistas tinham fracassado sistematicamente". Mas, desde os anos 1920, o país contava com "um dos partidos comunistas mais combativos e melhor armados ideologicamente para a luta de libertação e a luta operária". Trabalhadores assalariados, operários industriais e camponeses, "constituíam uma força potencialmente socialista". Homens "morais e valentes" tais como José Martí, Céspedes, e os mais novos, Fidel Castro, Carlos Rafael Rodriguez e outros, começaram uma nova história sobre três linhas de conduta: "uma democrática, uma humanista e uma comunista" (CASANOVA, 1987, p. 187).

Fidel Castro e os companheiros haviam estudado o marxismo e o leninismo e sabiam "que a revolução devia contar com as massas e estas precisavam estar conscientes - como ator coletivo - dos requisitos do sucesso". Mas, também, desde 1956, o grupo revolucionário ligou-se ao "setor mais atrasado e combativo", aos camponeses da serra, que queriam terras (CASANOVA, op. cit., p. 188-189)

O desenvolvimento da luta na serra, da luta de guerrilhas, não foi feito apenas na serra, nem só com armas. O grupo rebelde repartiu terra enquanto combatia, fundou escolas e hospitais, praticou uma educação política e militar dos camponeses combatentes e de seus próprios quadros (ibid., p. 190). 
A educação das massas foi uma das metas principais da Revolução Cubana desde o seu início em 1959. Seus princípios norteadores foram: o princípio do caráter massivo da educação, ou "a educação como um direito e um dever de todos é uma realidade em Cuba"; o que significa a educação para crianças, jovens e adultos, em todas as idades, sexo, grupos étnicos, religiosos, por local de residência ou por limitações físicas ou mentais, de modo a alcançar a universalização do ensino primário inicialmente e, progressivamente, o ensino secundário e superior (Pedagogia,93, 1993, p. 12, grifo nosso).

A nova educação teve início com uma ampla campanha de alfabetização que se iniciou logo após a Revolução, envolvendo toda a sociedade e contando com o deslocamento de jovens e maestros de outros países da América Latina para alfabetizar onde houvesse analfabetos, nos lugares mais distantes do país (MURILLO ET AL., 1995; ROSSI, 1981; BISSIO, 1985). Sistematizou-se o

princípio da combinação estudo e trabalho, que tem profundas raízes no ideário pedagógico de José Martí.

Segundo o Ministério da Educação (MINISTÉRIO, 1984), "O problema de como levar à prática na escola cubana a aplicação do princípio politécnico e laboral foi resolvido mediante o enfoque politécnico nos diferentes planos de estudo, o trabalho socialmente útil, as atividades extraescolares e a vinculação do estudo com o trabalho" (p. 111). Pelo princípio da participação de toda a sociedade nas tarefas da educação do povo, reconhece-se a sociedade como uma grande escola.

Não obstante a pressão internacional e, particularmente, o bloqueio econômico e político conduzido pelos Estados Unidos, Cuba tem, até hoje, os mais altos índices de universalização e qualidade da educação, em todos os níveis, comparáveis aos países ricos capitalistas.

\section{A pedagogia socialista do MST}

$\mathrm{Na}$ história da educação brasileira, a dualidade educacional é uma constante. Quando o desenvolvimento da indústria exigiu trabalhadores com alguma instrução, as elites no poder e seus intelectuais organizaram instituições educacionais para a assistência e o disciplinamento dos pobres e desvalidos; depois vieram sucessivas leis e reformas educacionais, destinando às classes de

TrabalhoNecessário- www.uff.br/revistatrabalhonecessario: ano 16, №29/2018 
baixa renda, aos trabalhadores, a rede primário-profissional, e às classes média e alta, a rede de ensino secundário-superior (CUNHA, 1998). Estudos mais recentes e atuais reafirmam até hoje, como o regime de acumulação capitalista, "ao aprofundar as diferenças de classe, aprofunda a dualidade estrutural como expressão cada vez mais contemporânea (...)" conservando o dualismo na educação (KUENZER, 2007, P. 1154). ${ }^{15}$

Este contraponto é importante para entender a análise de Puiggrós (op. cit.) e a presença inovadora da educação socialista pelo Movimento dos Trabalhadores Rurais sem Terra (MST) no Brasil. Sobre o socialismo, diz a autora que "todo objeto de estudo é construído a partir de posições ideológicas e políticas que necessariamente outorgam um determinado rumo à análise". E é inevitável "considerar que a sociedade socialista" é superior à capitalista pelos ideais de justiça social e de relações mais democráticas, ressalvando as contradições históricas de sua pretensa "infalibilidade pragmática, sobretudo com respeito à evolução autoritária que tiveram seus sistemas políticos" (p. 109-10).

A universalização da alfabetização e do acesso progressivo à escolaridade básica e científico-tecnológica até o nível superior deu às populações da URSS e de Cuba padrões só alcançados pelos países de capitalismo central. ${ }^{16}$ Eles são inspiradores para as mudanças que se pretende na educação pública nas escolas geridas com a participação do MST, que completa 30 anos de criação do setor educação nos estados como uma de "suas tarefas políticas". Roseli Caldart (2017) ${ }^{17}$ ressalta o novo ciclo de atuação "que se projeta pela inserção das escolas na construção da Reforma Agrária Popular" (CALDART, 2017, p. 262).

A autora apresenta quatro pressupostos que orientam a pedagogia socialista como horizonte prático e teórico do Movimento. Primeiro, "como o conjunto de esforços 'de associação e de teorização de práticas educativas protagonizadas pelos trabalhadores ao redor do mundo" de um ponto de vista de classe, para a "construção de novas relações sociais de caráter socialista"

\footnotetext{
${ }^{15}$ Basta citar a recente lei da Reforma do Ensino Médio, Lei. n. 13.415 de 2017, que retorna aos idos da Reforma Capanema nos anos 1940.

${ }^{16}$ Entre outros, ver Puiggrós (op. cit.), sobre detalhamento dos avanços do sistema educacional cubano (p.114 e ss.).

${ }^{17}$ Neste texto, trazemos apenas algumas notas sobre a pedagogia socialista do MST, de Roseli Caldart (2017) na comemoração dos 100 anos da Revolução Russa. Seu trabalho e de outros autores, a exemplo de Luiz Carlos de Freitas, Dermeval Saviani, Gaudêncio Frigotto, Roberto Leher, é parte do Seminário "Construção histórica da Pedagogia Socialista: legado da Revolução Russa de 1917 e desafios atuais", realizado em Guararema, S. P., 24 a 27 de maio de 2017.
}

TrabalhoNecessário- www.uff.br/revistatrabalhonecessario: ano 16, №29/2018 
(FREITAS, 2009, apud CALDART, 2017, p. 263). Segundo, a pedagogia do MST é entendida "como um esforço particular de construção concreta da pedagogia socialista". O MST "tem buscado vincular a educação às lutas de transformação social, desde a realidade atual do campo" (ibid.).

"Terceiro, a pedagogia socialista não cabe na escola. É muito mais ampla e se refere aos processos de formação dos lutadores e construtores do socialismo nos diferentes tempos e espaços educativos da vida social" (PISTRAK, 2015, apud CALDART, p. 264). A escola deve ter em conta a sintonia com "as circunstâncias de cada momento histórico, a formação social concreta (realizando as transformações e (as insubordinações) necessárias" (CALDART, ibid.).

Em quarto lugar, "os caminhos da transformação da escola na direção da pedagogia socialista implica enfrentar as contradições e os dilemas metodológicos da relação educação/escola e trabalho (...) Dar centralidade a esta relação em uma direção emancipatória exige uma nova lógica de organização do trabalho pedagógico" (ibid.).

Teoricamente, o MST iniciou seu trabalho com a leitura da Pedagogia do Oprimido de Paulo Freire e as palavras geradoras. Mas logo foi introduzida a leitura de Pistrak, Ensaios sobre a escola politécnica (2015) "que traz a organização de estudos pelo sistema de complexos". Pistrak também reivindica "uma escola que não fique aquém das exigências da vida" (apud CALDART, id., p. 265-66). Com Marx e Engels, aprofundou-se "a compreensão sobre o princípio educativo do trabalho" (id., p. 274).

A autora ainda chama a atenção para o trabalho do MST junto às escolas das áreas de reforma agrária; o II Congresso do MST, em 1990, que definiu como estratégia de luta "ocupar, resistir, produzir", a partir de dois diferenciais importantes, "o protagonismo dos trabalhadores rurais sem terra e suas organizações de luta pela terra e a organização coletiva do trabalho nos assentamentos, que se chamou de cooperação agrícola". De 1990 a 1991, a proposta de educação do MST firmava "a relação entre escola e trabalho (produção)" que remete às "formulações dos pedagogos russos sobre a autoorganização dos estudantes e a participação das crianças e dos jovens no trabalho produtivo" (id., p. 267, grifos da autora).

No momento, o trabalho educativo da escola está intimamente vinculado à Reforma Agrária Popular (RAP) que:

TrabalhoNecessário- www.uff.br/revistatrabalhonecessario: ano 16, №29/2018 
Assume o 'enfrentamento dos sujeitos trabalhadores contra as forças do capital'. É popular porque não se destina apenas aos trabalhadores sem-terra, mas visa todo o povo e somente será realizada por uma aliança do conjunto da classe trabalhadora, como tática vinculada a estratégia de luta contra o capitalismo e acúmulo de forças para mudanças estruturais na sociedade (MST, 2014, p. 46, apud CALDART, id, p. 276, grifos da autora).

\section{Considerações finais}

Retomamos nestas breves considerações, a exigência da historicidade na análise crítica do tema para que se possa compreender o papel das grandes revoluções do mundo ocidental e o ideário do conjunto de projetos educacionais da Rússia e de Cuba e, por último, do MST. Fundamentalmente, queremos significar a necessidade de situar os acontecimentos - fatos ou fenômenos, segundo outras interpretações teóricas - no contexto do tempo-espaço e das sociedades em que ocorrem, sob a ação dos sujeitos sociais que atuam segundo suas concepções de homem e de sociedade. Também significa assumir que toda ação, assim como toda apreciação crítica, contém as posições ideológicas e políticas dos sujeitos envolvidos nos processos, nas ações e na reconstrução histórica dos acontecimentos.

Todas as grandes revoluções são controversas pelos ideais que alimentaram e pela historicidade dos limites e características positivas, umas, negativas, outras, de sua realização. Todas influenciaram os povos e seus projetos de vida, entre os quais, os de educação. Foram sempre processos de luta pela reversão dos poderes constituídos, o que Christopher Hill chamou de "o mundo de ponta-cabeça”, ao relatar e analisar a Revolução Inglesa de 1640.

No mundo ocidental, outras grandes revoluções tiveram consequências semelhantes na transformação dos poderes constituídos e no ideário legado para outros povos. Foram as revoluções de pensamento e de cultura, o Renascimento e o lluminismo, a Revolução de Copérnico, a Reforma Protestante, a Revolução Científica de Darwin. Foram as revoluções de massas, a Revolução Francesa, a revolução liberal no contexto da Revolução Industrial. Afirmou os princípios de cidadania universal e o lema de Liberdade, Igualdade e Fraternidade, que permaneceu como um ideário sob o poder da burguesia, a submissão do trabalho 
ao capital, a prevalência do mercado em todo o mundo, hoje, globalizado na economia, na comunicação, na cultura.

Outra grande revolução foi a Revolução Russa, revolução socialista que destituiu os poderes constituídos aristocráticos. Inicialmente, deu voz e poder aos trabalhadores, camponeses e operários. Opôs-se ao imperialismo capitalista e universalizou a educação e a elevação do padrão de vida de toda a população, mas desenvolveu a economia com base no capitalismo de Estado, no autoritarismo e repressão. Deu inspiração e apoio à Revolução Cubana que, embora de menor abrangência, trouxe um novo ideário revolucionário, emancipador, principalmente, aos países dependentes do capitalismo na América Latina e na África.

Dentro de nosso tema principal, a pedagogia socialista, Puiggrós (1992) sintetiza a historicidade necessária à crítica: "A investigação pedagógica realizada sob o foco dos grandes paradigmas contemporâneos tende a estabilizar seus resultados, e a inclusão da visão histórica desordena o consenso imaginado no interior do sistema" (p. 97), do ideário alimentado pelos estados onde ocorreram as revoluções. A desorganização do consenso, aludida pela autora, é resultado de uma visão dialética dos processos sociais e educacionais, na perspectiva histórica das transformações como "síntese de múltiplas determinações" (MARX, 1977, aspas nossas).

Os projetos capitalistas de educação remetem sempre a uma educação dual, diferenciada em humanidades, letras e artes para os filhos das classes abastadas, encaminhados para o ensino superior e destinados aos postos de alto nível nos poderes executivo, legislativo e judiciário, além das carreiras de maior status e remuneração, a medicina, a engenharia e o direito. ${ }^{18}$ As revoluções socialistas caracterizam-se por processos diferenciados de participação das massas, sob o ideário democrático, dando-lhes acesso à educação, aos benefícios da riqueza social produzida pelo trabalho.

\footnotetext{
${ }^{18}$ No Brasil, entre as primeiras providências de $\mathrm{D}$. João $\mathrm{VI}$, quando veio para o Brasil, em 1808, foi a criação dos cursos de medicina, engenharia e direito. No Brasil, as universidades foram proibidas durante toda Colônia e o Império. Apenas em 1920, criou-se a Universidade do Brasil na lei.
} 
Concordando com Puiggrós, não significa que ela, nem nós, desconheçamos os rumos diferenciados da pedagogia socialista, face aos reducionismos mercantis da educação capitalista, mas que também a primeira também deve ser vista nas contradições engendradas por seus processos sociais, antes e depois da revolução.

Ao longo dos seus trinta anos de existência, o MST tem se destacado pela visão política democrática, pelo sentido de ampla participação dos trabalhadores na emancipação de todas as formas de exploração do trabalho e da desigualdade social; na conquista dos direitos básicos a uma vida digna (educação, saúde, alimentação, moradia, previdência, segurança); na posse da terra para a "soberania alimentar" com proteção à natureza, no direito social ao trabalho e efetiva participação social no projeto de país. No Brasil, a reforma agrária popular e a educação socialista são frentes de luta, cada vez mais árduas diante da ruptura institucional operada pelo golpe parlamentar, jurídico e midiático impetrado em agosto de 2016.

\section{Referências bibliográficas}

ABREU, Malila da G. R. Pedagogia Socialista. O legado da experiência educacional desenvolvida na Rússia pós-revolucionária. Curitiba; Appris, 2017.

AQUINO, Rubim S. L. de. Todo poder aos sovietes... A Revolução Russa e a formação da URSS. In: História das sociedades. Das sociedades modernas às sociedades atuais. Rio de Janeiro: Ao Livro Técnico, 1981.

BOTELLO, Ricardo M. La Escuela del Proletariado. La educación técnica industrial em México. 1876-1938. Puebla: Universidad Autónoma de Puebla, 1987.

BRAUDEL, Ferdinand. A longa duração. In: História e ciências sociais. Lisboa: Editorial Presença, 1982.

CALDART, Roseli Salete. et al. Dicionário Educação do Campo. Rio de Janeiro/São Paulo: EPSJV/Expressão Popular, 2012.

CALDART, Roseli Salete. Caminhos para transformação da escola: Pedagogia do MST e Pedagogia Socialista Russa. In: CALDART, R. S. e VILLAS BÔAS, Rafael, L. (orgs.) Pedagogia Socialista: legado da Revolução de 1917 e desafios atuais.

São Paulo: Expressão Popular, 2017. 
CAPRILES, René. Makarenko. O nascimento da pedagogia socialista. São Paulo: Scipione, 1989.

CASANOVA, Pablo González. História contemporânea da América Latina. Imperialismo e libertação. São Paulo: Edições Vértice, 1987.

CASTLES, Stephen; WUNSTENBERG, Wiebke. La educación del futuro. Una introdución a la teoria y prática de la educación socialista. México: Editorial Nueva Imagen, 1982.

CIAVATTA, Maria. Mediações históricas de relação trabalho e educação. Gênese da disputa na formação dos trabalhadores (1930-1960). Rio de Janeiro: Lamparina / CNPq / FAPERJ, 2009.

LOBO, Roberta. Pedagogia Socialista. Verbete, In: CALDART; Roseli S. et al. Dicionário da Educação do Campo. São Paulo: Expressão Popular, 2012, p. 561-568.

CIAVATTA-FRANCO, Maria. Questões polêmicas da relação trabalho e educação na sociedade industrial. In: (org.) Estudos comparados e Educação na América Latina. Buenos Aires: Livros do Tatu/São Paulo: Cortez, 1992, p. 63-90.

CUNHA, Luiz A. Ensino médio e ensino técnico: de volta ao passado? Educação e Filosofia, v. 12, n. 24, p. 65-89, jul. dez. 1998.

DEDDECA, Edgar. O nascimento das fábricas. 3ạ. ed. São Paulo: Brasiliense, 1985.

FREITAS, Luiz C. A luta por uma pedagogia do meio: revisitando o conceito. In: PISTRAK, Moisey M. A Escola-Comuna. São Paulo: Expressão Popular, 2009.

Expressão Popular, 2013.

Prefácio. In: Rumo ao politecnicismo. São Paulo:

FRIGOTTO, Gaudêncio; CIAVATTA, Maria.; RAMOS, Marise. (orgs.). Ensino Médio Integrado: concepção e contradições. São Paulo: Cortez, 2005b, p. 57-82.

FRIGOTTO, Gaudêncio; CIAVATTA, Maria. Trabalho como princípio educativo. In: CALDART, Roseli S. et al. Dicionário Educação do Campo. Rio de Janeiro/São Paulo: EPSJV/Expressão Popular, 2012.

GRAMSCI, Antonio. A alternativa pedagógica. Barcelona: Ed. Fontamara, 1981.

HILL, Christopher. O mundo de ponta-cabeça. Ideias radicais durante a Revolução Inglesa de 1640. São Paulo: Companhia das Letras, 1987.

HOBSBAWN, Eric J. A era das revoluções: Europa 1789-1848. 4‥ ed. Rio de Janeiro: Paz e Terra, 1982 
A era dos impériosl: 1875-1914. Rio de Janeiro: Paz e Terra,

1988.

IGLÉSIAS, Francisco. A revolução industrial. São Paiulo: Brasiliense, 1982.

JAPIASSÚ, Hilton. A revolução científica moderna. Rio de Janeiro: Imago, 1985.

KRUPSKAYA, N. K. A construção da pedagogia socialista. São Paulo: Expressão Popular, 2017.

KUENZER, Acácia. Da dualidade assumida à dualidade negada: o discurso da flexibilização justifica a inclusão excludente. Educação \& Sociedade, v. 28, n. 100, p. 1153-1178, out. 2007.

LUIEDMANN, Cecília da S. Apresentação. A pedagogia no solo da revolução. In: . Anton Makarenko. Vida e obra - a pedagogia na revolução. São Paulo: Expressâo Popular, 2002.

LUKÁCS, György. As bases ontológicas do pensamento e da atividade do homem. Temas de Ciências Humanas. São Paulo, no 4, 1978, pp. 1-18.

MAKARENKO, A. S. Poema pedagógico. Vol. I. São Paulo: Brasiliense, 1985.

MANACORDA, Mário. O principio educativo em Gramsci. Porto Alegre: Artes Médicas, 1990.

MARX, Karl e ENGELS, A ideologia alemã. (Feuerbach). Sâo Paulo: Ciências Humanas, 1979.

MARX, Karl. O capital. (Crítica da economia política). Rio de Janeiro: Civilização Brasileira, 1980.

Estampa, 1977.

Contribuição para a crítica da economia política. Lisboa: Editorial

MATTOS, Marcelo Badaró. Cotas, raça, classe e universalismo; revendo os argumentos do debate na perspectiva da luta pela transformação. In:_. Reorganizando em meio ao refluxo. Ensaios de intervenção sobre a classe trabalhadora no Brasil atual. Rio de Janeiro: Vício de Leitura, 2009, p. 203-220.

MINISTERIO DE EDUCACIÓN. Pedagogía. Trabajo coletivo de especialistas del Ministerio de Educación de Cuba bajo la dirección del Instituto Central de Ciencias Pedagógica.La Habana: Editorial Pueblo e Educación, 1984.

MURILLO, José et al. 5 maestros argentinos alfabetizaram en Cuba. Buenos Aires: Ediciones PERSPIR, 1995.

NOGUEIRA, Maria Alice. Educação, saber, produção em Marx e Engels. São Paulo: Cortez; Autores Associados, 1990. 
NOSELLA, Paolo. A escola de Gramsci. Porto Alegre: Artes Médicas, 1992.

PISTRAK, Moisey M. A Escola-Comuna. São Paulo: Expressão Popular, 2009.

Brasiliense, 1981. - Fundamentos da Escola do Trabalho. São Paulo:

PUIGGRÓS, Adriana. Três artigos sobre a educação socialista. In: (org.) Estudos comparados e Educação na América Latina. Buenos Aires: Livros do Tatu/São Paulo: Cortez, 1992, p. 91-136.

ROSSI, Wagner. Pedagogia do trabalho. Vol. 1. Caminhos da educação socialista. São Paulo: Moraes, 1982.

São Paulo: Moraes, 1982.

. Pedagogia do trabalho. Vol. 2. Raízes da educação socialista.

SAVIANI, D. A Nova lei da educação. Trajetória e perspectivas. Campinas, Autores Associados, 1997.

SCHULGUIN, Viktor N. Rumo ao politecnicismo. São Paulo: Expressão Popular, 2013.

SHEFFIELD, Gary. Revolução na Rússia. In: O conflito se arrasta. Tropas exaustas na ofensiva Nivelle e na Batalha de Passchendaele. Vol. 6. São Paulo: Folha de São Paulo, 2014.

SILVA, Kalina V.; SILVA, Maciel H. Dicionário de conceitos históricos. São Paulo: contexto, 2005.

TRAGTENBERG, Maurício. Pistrak: uma pedagogia socialista. In: PISTRAK. Fundamentos da Escola do Trabalho. São Paulo: Brasiliense, 1981.

Recebido em: 06 de dezembro de 2017. Aprovado em: 27 de fevereiro de 2018. Publicado em: 13 de junho de 2018. 